\title{
КАРТОГРАФИЧЕСКОЕ МОДЕЛИРОВАНИЕ ШУМОВОГО ЗАГРЯЗНЕНИЯ
}

\section{Ольга Николаевна Николаева}

Российский государственный аграрный университет - МСХА им. К.А. Тимирязева, Институт мелиорации, водного хозяйства и строительства имени А.Н. Костякова, Россия, 127550, г. Москва, ул. Тимирязевская, 49, доктор технических наук, профессор кафедры экологической безопасности и природопользования, тел. (499) 976-09-37;

Сибирский государственный университет геосистем и технологий, 630108, г. Новосибирск, ул. Плахотного, 10, профессор кафедры экологии и природопользования, тел. (383)361-08-86, e-mail: onixx76@mail.ru

\section{Наталия Владимировна Лагутина}

Российский государственный аграрный университет - МСХА имени К.А. Тимирязева, Институт мелиорации, водного хозяйства и строительства имени А.Н. Костякова, Россия, 127550, Москва, ул. Тимирязевская, 49, кандидат технических наук, доцент кафедры экологической безопасности и природопользования, тел. (499)976-09-37, e-mail: oie@rgau-msha.ru

В статье кратко охарактеризовано негативное воздействие шума на здоровье городского населения. Отмечена актуальность оценки акустического (шумового) загрязнения на территории г. Москвы. Обоснована роль ГИС-технологий в проведении подобных исследований. Перечислены современные подходы к исследованию и картографированию шумовой нагрузки городских территорий. Описаны исследования, ранее выполненные кафедрой экологической безопасности и природопользования РГАУ - МСХА имени К.А. Тимирязева в области изучения акустического загрязнения г. Москвы. Изложен опыт картографирования и анализа собранных статистических сведений в среде QGIS. Представлены созданные цифровые карты и их фрагменты. Сделаны выводы об особенностях пространственной локализации шумовых загрязнений. Сформулированы предложения по дальнейшему развитию исследований. Особо отмечен факт необходимости создания трехмерных картографических моделей городской застройки для более объективного анализа шумовой нагрузки.

Ключевые слова: шум, акустическое загрязнение, шумовое загрязнение, оценка шумового воздействия, экологическое картографирование, цифровые карты, ГИС, ГИС-технологии

\section{CARTOGRAPHIC MODELLING OF NOISE POLLUTION}

\section{Olga N. Nikolaeva}

Russian State Agrarian University - Moscow Timiryazev Agricultural Academy, Institute of Amelioration, water management and construction named after A.N. Kostyakov, 49, Timiryazevskaya St., Moscow, 127550, Russia, Professor, Department of Environmental Safety and Natural Resources Management; phone: (499)976-09-37, e-mail: onixx76@mail.ru

Siberian State University of Geosystems and Technologies, 10, Plakhotnogo St., Novosibirsk, 630108, Russia, D. Sc., Professor, The Department of Ecology and Natural Resources Management, phone: (383)361-08-86

\section{Natalia $V$. Lagutina}

Russian State Agrarian University - Moscow Timiryazev Agricultural Academy, Institute of Amelioration, water management and construction named after A.N. Kostyakov, 49, Timiryazevskaya St., Moscow, 127550, Russia, Ph. D., Associate Professor, Department of Environmental Safety and Natural Resources Management; phone: (499)976-09-37, e-mail: oie@rgau-msha.ru 
The article briefly describes the negative impact of noise on the health of the urban population. The relevance of the assessment of acoustic (noise) pollution on the territory of Moscow is noted. The role of GIS technologies in carrying out such studies is substantiated. The modern approaches to the study and mapping of the noise levels on urban areas are listed. The article describes the studies of acoustic pollution in Moscow previously carried out by the Department of Environmental Safety and Environmental Management of the Russian State Agrarian University - Moscow Agricultural Academy named after K.A. Timiryazev. A case study of mapping and analyzing the collected statistical information in QGIS is described. The created digital maps and their fragments are presented. Conclusions are made about the features of the spatial analysis of noise pollution. Proposals for the further research are formulated. The need to create three-dimensional cartographic models of urban environment for a detail analysis of the noise level was emphasized.

Keywords: noise, acoustic pollution, noise pollution, noise impact assessment, environmental mapping, digital maps, GIS, GIS technologies

Шум является одним из ведущих факторов, оказывающих негативное воздействие на качество жизни и уровень здоровья жителей крупных городов. Постоянное превышение уровня шума свыше 40 дБ (громкость обычного разговора) приводит к угнетению центральной нервной системы вплоть до неврозов, нарушению обмена веществ, язве желудка, обострению гипертонии и профессиональных заболеваний [1]. При этом 60\% горожан имеют нормальную чувствительность к шуму 30\% являются сверхчувствительными, и лишь 10\% нечувствительны [2].

Москва обладает одной из крупнейших систем наземного городского транспорта, перевозящей ежедневно более 7 млн. пассажиров $[3,4]$. А с учетом постоянного роста населения города возрастает и количество людей, постоянно подвергающихся избыточному шумовому воздействию.

Распределение шумовой нагрузки по территории населенного пункта в значительной степени обусловлено особенностями планировки городской территории (конфигурация дорожно-транспортной сети, локализация промышленных и социально-культурных объектов, оборудованных вентиляционными установками, громкоговорителями и прочими источниками шума, и т. п.). Однако при этом уровень шума может сильно варьироваться в пределах одного и того же локального участка местности в силу наличия зеленых насаждений и шумовых экранов, ориентировки зданий и прочих местных факторов. Поэтому при изучении закономерностей формирования шумовых загрязнений в населенных пунктах важную роль играют геоинформационные методы сбора, анализа и моделирования исходных данных, а в качестве одного из основных инструментов для разработки шумозащитных мероприятий выступают цифровые и электронные карты и картографические модели.

В настоящее время наиболее распространены следующие подходы к картографированию шумового загрязнения городов:

- создание карт по данным полевых измерений, выполняемых с применением шумомеров в заранее определенных точках местности. Объектом картографирования в этом случае являются эквивалентные уровни шума, скорректированные в зависимости от частоты звука и измеряемые в децибелах.

- оценка шумовой нагрузки по косвенным показателям (особенности транспортного потока, характер застройки территории и пр.). Объектом картографирования являются характеристики транспортного потока (интенсивность 
и объем движения, состав и плотность потока), относительно которых затем рассчитывается шумовая нагрузка.

Оба подхода имеют свои достоинства и недостатки, однако общим для них является наличие значительного объема полевых измерений уровня шумовой нагрузки. Это обусловлено главенствующей ролью инструментального метода в акустических исследованиях [5]. Упростить и ускорить процесс формирования массива исходных данных позволит использование GPS-технологий для фиксации координат точек отбора проб и ГИС-технологий для последующего моделирования уровней шума на прилегающих территориях.

В 2014 г. кафедрой экологической безопасности и природопользования Института мелиорации, водного хозяйства и строительства имени А.Н. Костякова РГАУ-МСХА имени К.А. Тимирязева были начаты исследования акустического загрязнения на территории г. Москвы. Использовался первый из вышеописанных подходов. С помощью шумомера были проведены измерения уровня шума от наземного транспорта у фасадов домов первой линии застройки [3]. Измерения выполнялись на транспортных артериях 4 категорий: магистральные улицы общегородского значения 1 и 2 класса, магистральные улицы районного значения, улицы районного значения, прочая дорожная сеть. Всего было охвачено порядка 100 точек наблюдения, рассредоточенных по территории города. Конфигурация сети наблюдений представлена на рисунке 1. На каждой точке определялись шумовые нагрузки источника шума, уровень шума (в децибелах) и расстояние до источника шума.

На основании собранных данных в QGIS были созданы база данных и ряд цифровых карт, отображающих различные аспекты шумового загрязнения территории (рис. 1-3).

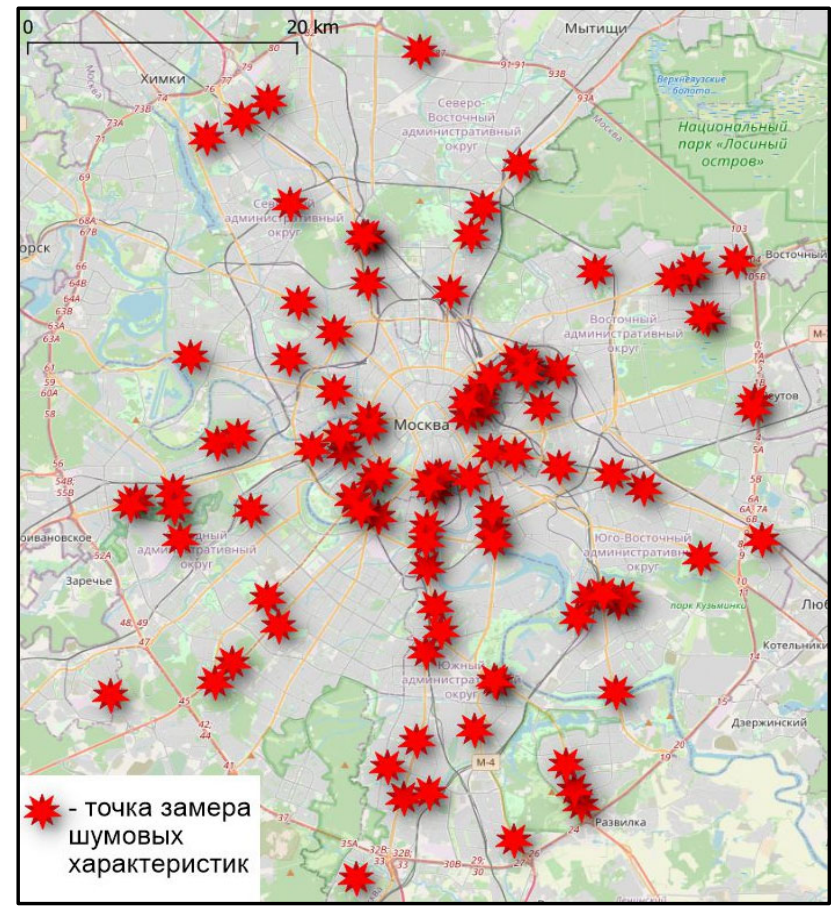

Рис. 1. Сеть измерений шумовой нагрузки

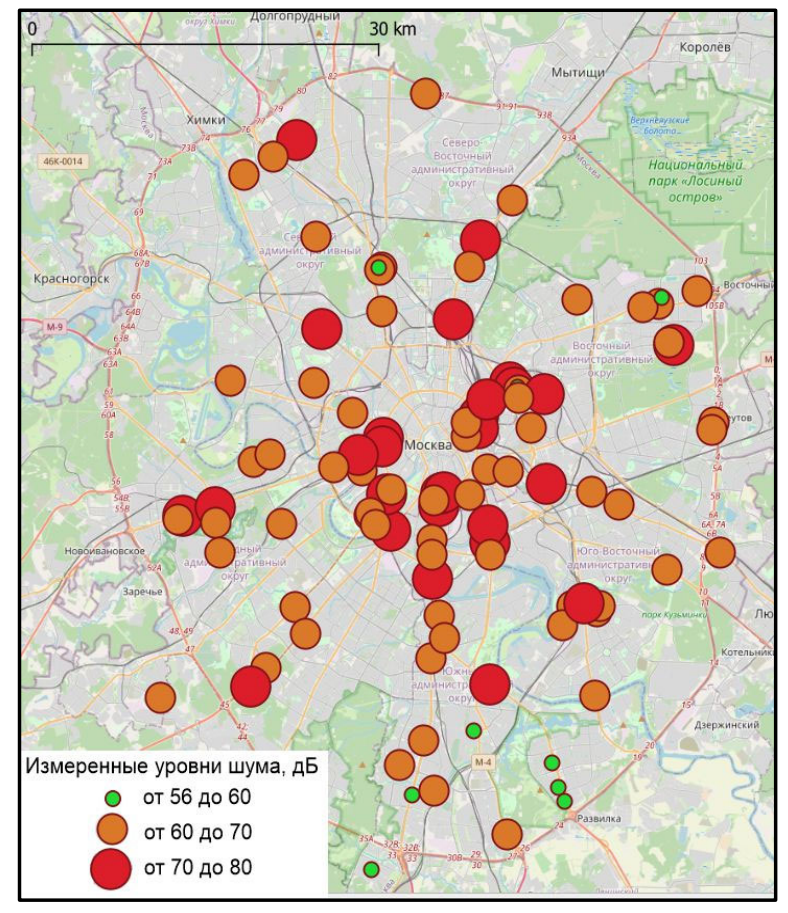

Рис. 2. Уровни шума на точках наблюдения 
Ранжирование результатов измерений позволило разбить все точки замера на 3 категории: с уровнем шума менее 60 дБ, от 60 до 70 дБ, и более 70 дБ (рис. 2). Следует заметить, что в соответствии с действующими нормативными документами [6] в точках последней, третьей, категории наблюдается превышение установленных нормативов, в соответствиями с которыми уровень уличного шума не должен превышать 70 дБ в дневное время и 60 дБ в вечернее [7].

Более детальное моделирование площадного распространения шумовых загрязнений по территории, прилегающей к точкам отбора проб, выполнялось в среде QGIS встроенными средствами геоинформационного анализа. В ходе экспериментальных работ оптимальным было признано использование IDWинтерполяции, однако в своем стандартном исполнении она осуществляет построение изолиний без учета объектов местности, препятствующих распространению шума (рис. 3).

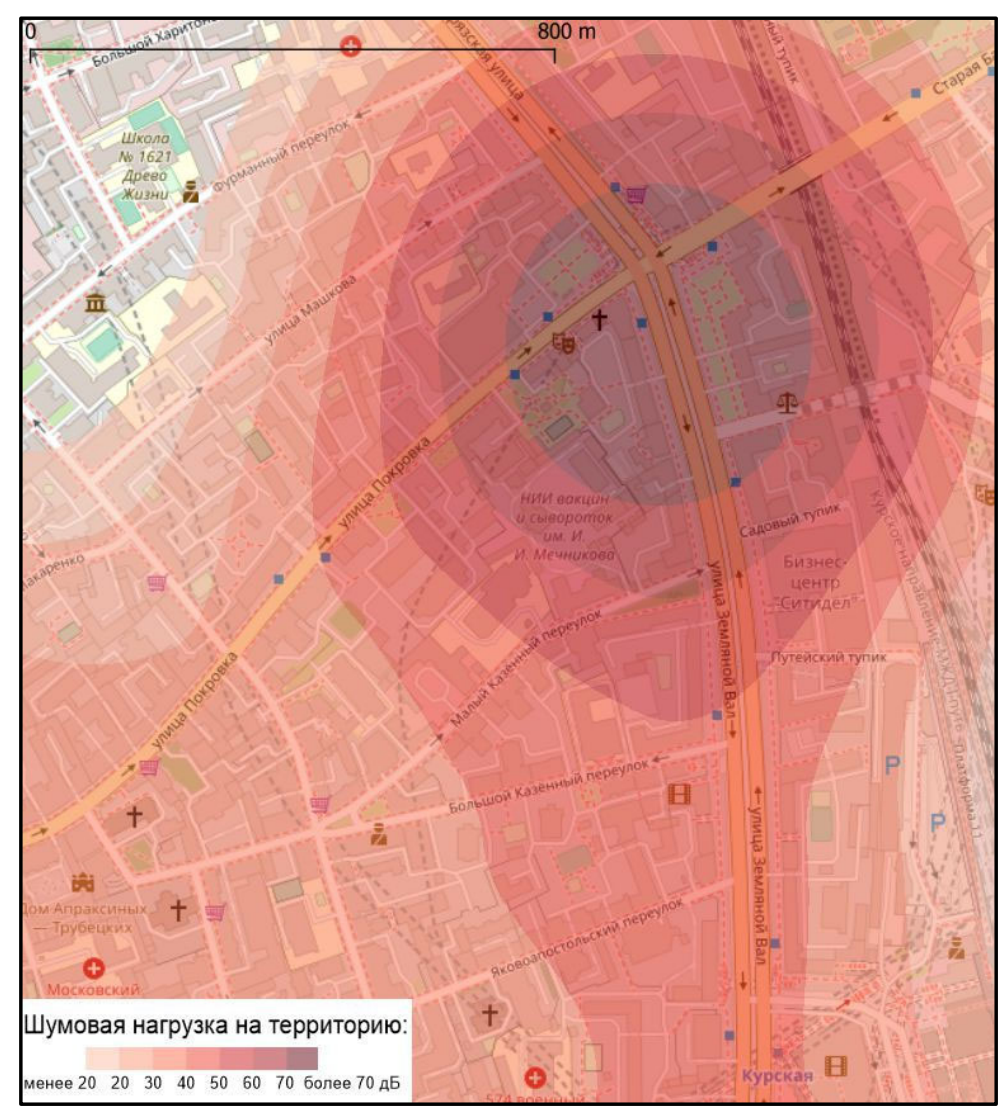

Рис. 3. Изолинейное моделирование шумовой нагрузки на территорию (фрагмент созданной карты)

В целом анализ созданных картматериалов позволил установить следующее:

- высокий (выше 60 дБ) уровень акустического загрязнения наблюдается на городских транспортных путях всех категорий: от магистральных улиц общегородского значения до улиц районного значения. Карта, представленная на рис. 2 , наглядно демонстрирует, что Москва уже переросла тут стадию, на которой 
уровень шума можно связывать с категорией городской улицы. Поэтому если ранее (еще в начале 2000-х годов) имело смысл планировать исследования, в первую очередь охватывая измерениями основные проезды по городу, то возможно теперь целесообразно использовать сеть наблюдений с более регулярной конфигурацией (за вычетом территорий, занятых парками, скверами, ООПТ и водными пространствами);

- участки с превышающим нормативы (выше 70 дБ) уровнем акустического загрязнения лоцируются не только в центральной части города, но и за ее пределами, причем не всегда соблюдается ожидаемая тенденция их корреляции с многополосными магистральными улицами (шоссе). Поэтому целесообразно в перспективе запланировать основной массив полевых измерений на территориях, расположенных между третьим транспортным кольцом и МКАД;

- в условиях почти повсеместного превышения общего шумового фона на территории города становится актуальной детальная оценка шумового загрязнения локальных территорий (на уровне квартала) с учетом градостроительных факторов, влияющих на распространение шума (застройки, зеленых массивов). Для этого планируется реализация средствами QGIS трехмерной модели городской застройки на район экспериментальных работ в черте Москвы.

Вышеуказанные пути осуществления дальнейших исследований с применением ГИС-технологий позволят повысить объективность оценки акустического загрязнения городских территорий и заложат информационную основу для разработки шумозащитных мероприятий.

\section{БИБЛИОГРАФИЧЕСКИЙ СПИСОК}

1. Лыков И. Н., Николаева Т. С., Рахимов К. В. Экологические и социальные аспекты шумового загрязнения окружающей среды // Экология урбанизированных территорий. -2019. № 2. - С. 80-84.

2. Погонышева И.А., Погонышев Д.А., Крылова А.А. Влияние шума на психофизиологические параметры и работоспособность организма человека // Вестник Нижневартовского государственного университета. - 2015. - № 1. - С. 87-93.

3. Лагутина Н. В., Новиков А.В., Сумарукова О.В. Оценка изменения уровня шума от наземного транспорта г. Москвы // Материалы VIII Всеросс. науч-практ. конф. с междунар. участием «Защита от шума и вибрации», 19-21 марта, Санкт-Петербург. - 2019. - С. 534-542.

4. Оценка социально-экономического эффекта публикации открытых данных на примере данных общественного транспорта Москвы / Р. Е. Артамонов, С. Б. Датиев, А. Б. Жулин и др.; Нац. исслед. ун-т «Высшая школа экономики», Центр анализа деятельности органов исполнительной власти. - М.: Изд. дом Высшей школы экономики, 2015. - 92 с.

5. Новиков А.В., Сумарукова О.В. О методах проблемного обследования ООПТ в рамках учебной практики // Управление объектами недвижимости и развитием территорий: сб. ст. междунар. науч.-практич. конф. / Под ред. В.А. Тарбаева. Саратов: ФГБОУ ВО Саратовский ГАУ, 2017. - С. 274-277.

6. Свод правил СП 42.13330.2011 «Градостроительство. Планировка и застройка городских и сельских поселений» / утв. Приказом Минрегион России от 28 декабря 2010 г. № 820. 542. [Электронный ресурс]. - Режим доступа: http://docs.cntd.ru/document/1200084712.

7. СП 51.13330.2011 Защита от шума. Актуализированная редакция СНиП 23-03-2003 (с Изменением № 1) [Электронный ресурс]. - Режим доступа: http://docs.cntd.ru/document/1200084097. 